Fig. 1 represents the ultra-violet absorption of aqueous solutions of $\mathrm{L}$-ascorbic acid at acid and neutral $p \mathrm{H}$ values.

Research Centre,

J. S. LAWENDEL

Italfarmaco S.p.A.,
Piazza Coriolano 5,
Milan. April 11 .

'Lawendel, J. S., Nature, 178, 873 (1956).

\section{Hexagonal Chromium Crystals from Fused Electrolytes}

THE meaning of the hexagonal structure sometimes observed in chromium electroplates has been the subject of considerable study. The present communication is to record some observations on chromium produced by electro-refining in fused-salt baths. The particular bath used in the production of the chromium described here consisted of sodium chloride, chromium chlorides, and dissolved metallic sodium at $800^{\circ} \mathrm{C}$. The cathode deposit consisted of a layer of fine crystals in salt and coarse idiomorphic chromium crystals attached to them.

The coarse crystals were in the form of hexagonal plates and rods as shown in Fig. 1. Fig. 2 shows some of the rods bent to show their ductility. Both pictures are at about twice natural size. X-ray examination shows the plates to be body-centred

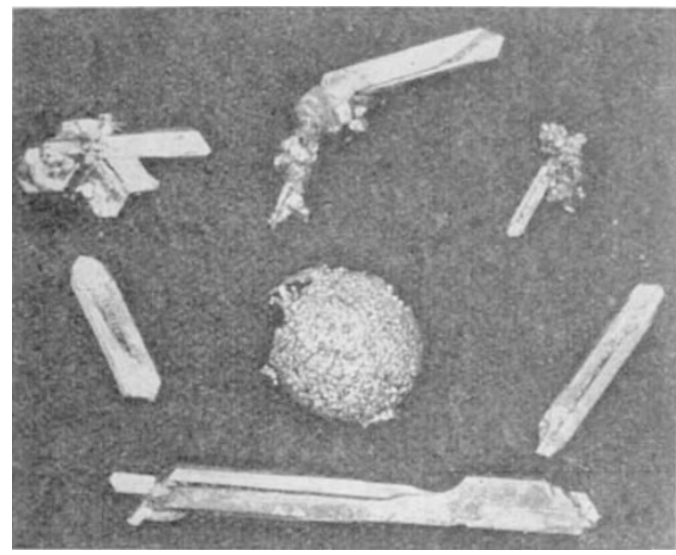

Fig. 1

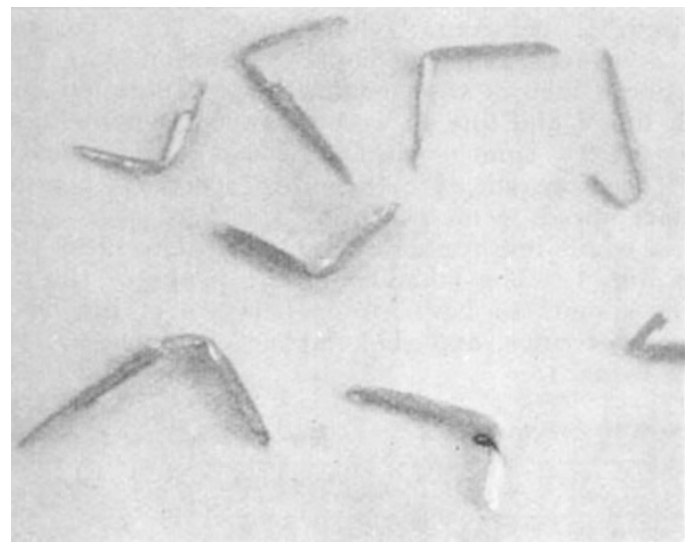

Fig. 2 cubic, so that they are pseudomorphs after the hexagonal form.

We regard it as improbable that the hexagonal form is stable at $800^{\circ} \mathrm{C}$, , but think rather that it represents formation of an unstable modification under the particular conditions. 'The crystals have a density of $6 \cdot 9$, and a hardness of about $130 \mathrm{DPH}$.

The layer of fine crystals formed in the salt layer has the lowest electrical resistance reported for chromium, namely, 3.6 microhms $/ \mathrm{cm}$.

$$
\begin{aligned}
& \text { R. S. Dean } \\
& \text { F. X. McCawley }
\end{aligned}
$$

Chicago Development Corporation, Riverdale, Maryland.

\section{A Performance Index for Gas Chromatographic Columns}

J. Friend and E. Watson have suggested that if an adequate 'performance index' could be defined for gas chromatographic columns, a much-needed clarification could be achieved in the interchange of data among experimenters.

A theoretical study of gas chromatographic columns has indicated that the following expression is reasonably invariant under a large range of conditions, and has other properties which commend it as a performance index :

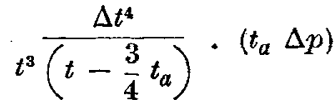

where $\Delta t$ is width of 'band' at mid-height; $t_{\alpha}$ is time interval between injection and centre of 'air peak'; $t$ is time interval between injection and centre of band; and $\Delta p$ is pressure drop across column; all times are in seconds, $\Delta p$ in dynes $\mathrm{cm} .{ }^{-2}$.

The theoretical basis for the expression given above, the smallness of which constitutes the desirable property, is too lengthy to give here, but its severel properties will be mentioned briefly.

(1) When the column is operated at the optimum flow-rate for band separations, the performance index constitutes a parameter depending essentially upon the packing material of the column; it is invariant with the column diameter and length, and to a large extent with the proportion of oil in the substrate of a gas-liquid partition column.

(2) If written as follows:

Performance index $=\left(\frac{\Delta t}{t-t_{a}}\right)^{4} \times \frac{\left(t-t_{a}\right)^{4} t_{a}}{t^{4}\left(t-\frac{3}{4} t_{a}\right)} \cdot(t \Delta p)$

the first term of the expression is proportional to the fourth power of the relative 'band width', which is analogous to the spectral slit-width of the spectroscopist, and inversely proportional to the resolving power; the second term is a maximum when $t=4 \cdot 3 t_{a}$, which indicates that, other things being equal, optimum separation of a given pair of components will occur when the capacity of the static phase for these components is a little more than three times the capacity of the mobile phase; and the third term may be considered as the 'price' paid for separation, in terms of the time of waiting required for the elution of the slowest component, and of the pressure drop across the column.

The spectrometrist who works in the far infra-red region and utilizes slit openings which are much 